\title{
ZAPAŽANJA O OPKORAČENJU U PREPISCI SVETOZARA PETROVIĆA**
}

Rad donosi segmente prepiske prof. Svetozara Petrovića sa inostranim kolegom prof. Džejmsom Bejlijem o kompleksnosti anžambmana. Diskusija zasnovana na istovetnom interesovanju doprinela je bogaćenju značenja ove oblasti, odnosno nadogradila je sva dosadašnja tumačenja ovog pojma nudeći dodatne implikacije njenog proučavanja. Ujedno se i prethodna zapažanja i razna gledišta predočena u Petrovićevim spisima o stihu preciziraju. Nadasve, ističe se značaj kulturološke kontekstualizacije ove metričke pojave i njena povezanost sa različitim tradicijama čitanja poezije.

Ključne reči: Svetozar Petrović, Džejms Bejli, opkoračenje, pauza na kraju, tradicije čitanje redaka, skandiranje, nenaglašena rima, nužno opkoračenje, neperiodsko opkoračenje - stil dodavanja, Peri i Lord.

\section{UVOD}

U rukopisnoj ostavštini prof. Svetozara Petrovića, u porodičnom vlasništvu, nalazi se bogata prepiska sa jednim profesorom Univerziteta $u$ Viskonsinu, Džejmsom Bejlijem (James Bailey), koja je gotovo u celini fundirana na metričkim pitanjima. Imajući u vidu činjenicu da je akademik Petrović bio jedan od naših najeminentnijih proučavalaca oblasti stiha, te da su sve do danas, a sa sigurnošću možemo reći da će i nadalje biti, zapažanja ovog versologa neizostavna svim istraživačima ovoga polja, kao i onima čija su naučna usmerenja prema pesništvu uopšte, nesporno se uviđa relevantnost opservacija u pismima, kojima bi se upotpunila viđenja pojedinih metričkih pojava. Ne sme se zanemariti ni činjenica da

\footnotetext{
* sanja.paripovic@ff.uns.ac.rs

** Rad je nastao u okviru projekta Aspekti identiteta $i$ njihovo oblikovanje u srpskoj književnosti (broj 178005), koji se uz finansijsku podršku Ministarstva prosvete i nauke RS sprovodi na Odseku za srpsku književnost Filozofskog fakulteta u Novom Sadu.
} 
je nadogradnja spektra značenja posebnih pojava indukovana i razmenom iskustva. Međutim, uvid u pisma, koja u tom specifičnom „dijaloškom darovanju iskustava” pružaju nova saznanja, doveo nas je u poziciju neophodne retrospektive, te inicirao „zamisao sažimanja tumačenja pojedinih pojmova u celokupnim njegovim radovima o stihu", odnosno privilegovanost susreta sa dragocenim raspravama o zasebnim pitanjima u pismima podstakao nas je da se osvrnemo na postojeća zapažanja o istom ranije izrečena u brojnim Petrovićevim spisima o stihu. „Činjenica da je korespondencija pokrenuta 1994. godine, a da su spisi o stihu napisani i saopšteni osamdesetih godina, ide u prilog ideji dopune, proširenja opsega interesnog područja ili razmatranja neukazanog aspekta određenog problema" (Paripović Krčmar 2018: 470).

U cilju kompletne karakterizacije pojmova pošli smo od pitanja opkoračenja, jedne od prvih pokrenutih tema za razgovor dvojice kolega čija su istovetna interesovanja rezultirala gotovo osmomesečnom (od januara do avgusta 1997. godina) diskusijom o kompleksnosti anžambmana. ${ }^{1}$

\section{RAZGOVOR NA TEMU OPKORAČENJA}

14. januar 1997.

\section{Dragi kolega, ${ }^{2}$}

Drago mi je da smo konačno u mogućnosti da se vidimo pa makar i na kratko. Nekako na Jakobsonovoj [Ромáн О́сипович Якобсо́н] konferenciji nije

\footnotetext{
${ }^{1}$ Napominjemo i da smo, usled obimnosti gledišta i konstatacija, kako u spisima o stihu tako i u pismima, kao i zbog žanrovske specifičnosti i hronologije, razdvojili problematizaciju ovoga pitanja, te upućujemo na rad koji prethodi ovoj priređenoj prepisci, rad u svojstvu propedeutičkog teksta prepisci, koji sa viđenjima u korespondenciji koja slede u daljem tekstu čini mogućim integralno obličje ovog termina (v. Paripović Krčmar 2018: 469483).Izdvajamo u ovih pet pisama, koje smo preveli sa engleskog, samo ključne segmente o ovom pesničkom postupku, izostavljajući neke podatke o ličnim životnim situacijama, o knjigama koje su razmenjivali i pozdrave upućene drugim kolegama. Uglaste zagrade označavaju deo teksta koji smo izostavili; izdvajanjem zagrada u zaseban red ukazujemo na izostavljanje čitavog pasusa; napomene priređivača takođe su u uglastim zagradama. Podvlačenja unutar pisama su načinili korespondenti. Neke termine ostavljamo u originalu jer se i u našem jeziku u tom obliku, samo transkribovani, koriste. Svi komentari u fusnotama su naši.

${ }^{2}$ Pismo kucano pisaćom mašinom na engleskom.
} 
bilo mnogo vremena za susret i razgovor sa ljudima. Hvala puno što si mi dao separate tvojih radova - posebno sam zainteresovan za onaj o opkoračenju koji je izrodio zanimljivo pitanje. Moj utisak je da engleski čitaoci obično ne zastaju na kraju retka kada je jako opkoračenje prisutno, ali se čini da je u ruskoj tradiciji obrnuto - svi sa kojima sam pričao kažu da oni automatski prave pauzu na kraju retka čak i kad se završava proklitikom, što se često dešava, na primer, u poeziji Brodskog [Ио́сиф Алекса́ндрович Бро́дский]. Kakva je situacija u srpskom? Da li pravite pauzu čak i u dramskom ili narativnom slobodnom stihu?

[...]

Sve najbolje,

Džejms Bejli ${ }^{3}$

Dragi profesore Bejli, ${ }^{4}$

15. februar 1997. [...]

Bio si dovoljno nemaran, u tvom pismu, da pokažeš interesovanje za pitanje za koje sam i sam zainteresovan, ali nisam primetio da iko pokazuje stvarno interesovanje za to. Dugo pismo koje sledi je sigurno preteška kazna za minornu nesmotrenost, ali - jednom kad je eventualno zainteresovan slušalac bio na vidiku nisam mogao da odolim da pišem o tome.

Tvoje pitanje - da li čitaoci na srpskohrvatskom prave pauzu na kraju retka kada je prisutno jako opkoračenje? - bilo je pitanje koje sam istraživao pre nekih petnaest godina kada sam slomio nekoliko rebara u nesreći i bio vezan za postelju nekoliko nedelja. Moju građu su činila izvođenja nekoliko drama u stihu i veliki broj poetskih recitala različitih vrsta emitovana putem radija. Moja rebra su zacelila pre nego što sam bio u mogućnosti da zaključim svoje istraživanje, i sada ne mogu čak ni da lociram moje beleške o tome (koje su, sećam se, sadržale i izrađenu klasifikaciju i neku inicijalnu statistiku).

Ali se sećam da su moji preliminarni zaključci usklađeni u velikoj meri sa mojim glavnim očekivanjima (zasnovani na ranijoj nesistematičnoj opservaciji ponašanja mnogih pojedinačnih čitalaca). Što se tiče osnovnog pitanja: pauza ili ne pauza, oba načina čitanja su registrovana u materijalu, svaki tip, uopšteno govoreći,

3 Iznad imena stoji potpis Dž. Bejlija. Ispod se nalaze podaci o mestu boravka $\mathrm{i}$ univerzitetska imejl adresa.

${ }^{4}$ Pismo kucano pisaćom mašinom na engleskom. Nije potpisano. 
pripada vrsti čitalaca. Po mojoj proceni dve tradicije čitanja / dve vrste čitalaca mogu se razlikovati kao /sa pauzom/ više tradicionalni, ili staromodni (sa svim konotacijama koje to ima u srpskohrvatskom), i /bez pauze/ moderni i urbaniji. Naravno, podrobnije gledano, situacija se ispostavila komplikovanijom. Bilo je čitalaca koji su se odnosili različito prema različitim vrstama opkoračenja (i opkoračenjima u različitim vrstama poezije). Bilo je takođe slučajeva u kojima se činilo nepodesno smestiti nečije čitanje u jednu od dve kategorije na osnovu pauze kao kriterija. (Moja prvobitna želja bila je da vidim da li je mesto opkoračenja u usmenoj interpretaciji markirano na bilo koji način glasom, i u stvari bilo je markirano na više načina pored jednostavne pauze: sporijim ili bržim čitanjem redova obuhvaćenim opkoračenjem, podizanjem ili spuštanjem nivoa na kraju retka, različitom realizacijom prvog naglaska u sledećem retku, itd.).

Izvesno vreme, na osnovu podataka u mom materijalu, bio sam u iskušenju da identifikujem dve vrste čitalaca kao poete koji čitaju sopstvenu poeziju, s jedne strane, i profesionalne glumce koji čitaju poeziju iz različitih perioda i glume $u$ stihovanim komadima, s druge strane. Ali, nakon izvesnog razmatranja i na osnovu mojih ranijih iskustava sa brojnim običnim čitaocima, odbacio sam to iskušenje. Bilo je to, zaključio sam, zbog karakteristike mog materijala gde je vidljivi vrh jednog od dva ledena brega bio stvarno nastanjen uglavnom pesnicima, a drugi uglavnom glumcima. Što se pesnika tiče, moj materijal je uključivao nužno samo pesnike koji su pisali u kanonski utvrđenim formama u vreme kada je ova vrsta stiha bila sama po sebi jaka odlika tradicionalizma, i, pored toga, prvenstveno one pesnike koji su uživali da čitaju svoju poeziju javno (i radili to obično na zategnut i glasan oratorski način); neki od najboljih savremenih S. i C. ${ }^{5}$ pesnika su retko, ako su ikada, čitali sopstvenu poeziju na pozornici (i u privatnim čitanjima izbegavali oratorsko recitovanje). Što se glumaca tiče, rezultate je trebalo vrednovati na osnovu činjenice da je čitanje bez pauze bilo poželjno za studente drame tokom poslednje decenije (kao što sam bio u mogućnosti da zaključim iz udžbenika dikcije, korišćenim u ovim školama, i iz drugih objavljenih radova predavača tog predmeta u tim školama, njihovo snažno opiranje „mehaničkoj privrženosti formalnim karakteristikama u oralnoj interpretaciji teksta" bilo je u radikalnom kontrastu sa onim što su similarni udžbenici sugerisali u ranijim godinama ovoga veka). ${ }^{6}$

\footnotetext{
${ }^{5}$ Verovatno se misli na srpske i hrvatske pesnike (serbian and croatian).

${ }^{6}$ Uz ovaj pasus na levoj margini stoji rukom pisano na srpskom: Đo[u]rđević 1970, 200, 225, 247, a ispod toga Ružić (ostatak nečitak; moguće Rečnik knj.[iževnih] ter.[mina]).
} 
Stoga, mislim da u srpskohrvatskom dva načina interpretacije opkoračenja u čitanju - „ruski” i „engleski” - treba da budu shvaćena kao dve još uvek koegzistirajuće ali istorijski određene konvencije: prvi način od strane nekih ljudi sada viđen kao tradicionalan (u potvrdnom smislu reči) i podesan za poeziju, i po drugima kao zastareo i anahron; drugi način viđen od strane iste grupe ljudi bilo kao uzimanje prevelike slobode prema formi, ili kao prirodniji i verniji značenju pesme.

Moje sledeće pitanje, pre petanaest godina, ticalo se mogućnosti da dve konvencije u stvari predstavljaju dve faze u zajedničkoj evropskoj istoriji čitanja poezije tokom dva poslednja veka. Nisam daleko odmakao u istraživanju ovog pitanja, ali sam napravio nekoliko nasumičnih. Na primer, proverio sam nekoliko popularnih udžbenika na engleskom objavljenih pre Prvog svetskog rata i ispostavilo se da, kad god su oni ponudili bilo kakvo mišljenje o temi, to je bilo različito zastupanje od „ruskog” čitanja. Upravo gledam jednu od tih knjiga, nasumično odabranu (u mom kabinetu u Akademiji držim veliku količinu mojih knjiga o stihu, ova se slučajno našla kod kuće), R. M. Aldenovu [Raymond Macdonald Alden] An Introduction to Poetry, New York 1909. Na strani 261-264 piše o ,pauzi na kraju” (pod aspektom napetosti između „retoričke fraze” i ,stihfraze") i u razmatranju opkoračenja slaže se da, ,čak i kada je malo ili nimalo retoričke pauze naznačeno, dobar čitalac može lako napraviti blagu metričku pauzu na kraju stiha... Bez obzira koliko smo slobodni u čitanju redaka, poezija nije dobro čitana ukoliko slušalac ne može da je razlikuje od proze."

Shvatio sam iz tvog pisma da je u ruskom jeziku tradicija čitanja redaka sa pauzom još uvek postojana. To je veoma interesantno. U Rusiji, međutim, čini se da je skandiranje - u užem smislu odgovarajućih nemačkih, ruskih i srpskohrvatskih reči, što se odnosi na standardan način čitanja poezije u školama u većem delu Evrope u 19. veku, sa strogom privrženošću pretpostavljenoj idealnoj metričkoj shemi - zadržalo važnost duže nego bilo gde drugde (ne znam za ozbiljnu knjigu u ovoj oblasti objavljenu na drugom mestu u Evropi tokom dvadesetih godina ovoga veka koja se bavi skandovkom_na način na koji je to obrađeno u Teoriji književnosti Tomaševskog [Бори́с Ви́кторович Томаше́вский]!). Ali u skorije vreme, mislim, da su se stvari promenile i da savremene ruske referentne knjige, koje upravo uzimam nasumično, čini se ukazuju samo na propedeutičko pedagošku vrednost skandiranja i skandovke. ${ }^{7}$ Ukoliko sam u pravu u pretpostavci da su skandiranje i „rusko” čitanje redaka elementi istog načina čitanja poezije - regulisana pravilom da svi stihovi u usmenoj interpretaciji treba jasno da ukazuju na njihov stihovni

\footnotetext{
${ }^{7}$ Uz ovaj pasus stoji na levoj margini rukom pisano: KLE (ostalo je nečitko).
} 
oblik - još uvek nepoljuljana ruska tradicija čitanja opkoračenja može se smatrati reliktom starog sistema (njegovo preživljavanje je, možda, potpomognuto još uvek široko rasprostranjenom praksom čitanja poezije javno?).

Naravno, sub specie aeternitatis, obe tradicije usmene interpretacije su podjednako legitimne. Ali, kakav god osećaj imao o dve tradicije kao čitalac poezije (i šta god mislio o njima kao proučavalac recitovanja), kao proučavaocu stiha donekle mi smeta tradicija skandiranja, odnosno njeno remećenje našeg opisa stiha. Primeri ovoga su povremena pretpostavka istraživača u analizi ritma da je skandiranje prisutno (prihvatiti ga u principu znači obesmisliti statistički postupak kao takav), ili tendencija istraživača da negira postojanje metričkih fenomena koji su retki ili neuobičajeni za određenu vrstu stiha (uporedi moj tekst „Opkoračenje u

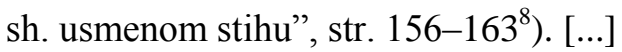

S najboljim željama, tvoj ${ }^{9}$ [Sveto]

Dragi Svetozare, ${ }^{10}$

22. mart 1997.

$[\ldots]$

Zaista želim da ti naposletku napišeš članak o opkoračenju zato što si fokusirao problem bolje od svih drugih koje sam čitao. Kada sam radio na svojoj knjižici o engleskom stihu pre više od dvadeset godina čitao sam razne tekstove o opkoračenju i pronašao mnogo zanimljivih stvari, ali ti si to prvi smestio u evropski kontekst i povezao to pitanje sa tradicionalnijim i modernijim načinom recitovanja poezije. Na prelazu dva veka postojala je grupa zvana „Petersburg Tests Committee" (Pitsburg na Floridi, ne u Rusiji), koju je interesovalo da otkrije autorstvo izvesnih elizabetanskih komada i u nekim slučajevima čak i izvođenje tih komada. Jedan od lingvističkih kriterijuma koji su koristili (sa statistikom) bio je „run-on lines”, 11 , drugi termin za opkoračenje.

Proučavao sam jampski tetrametar u engleskom pesništvu od 17. do početka 20. veka i razni ljudi su mi čitali mnoge pesme. Uglavnom sam to radio

\footnotetext{
${ }^{8}$ Tekst je objavljen u zborniku Usmeno i pisano/pismeno u književnosti $i$ kulturi, Colloquia Litteraria, knj. 4. Ur. Svetozar Petrović. Novi Sad: VANU, 1988, 139-168. (Novi Sad: Prosveta, 1989) (zbornik je štampan ćirilicom).

${ }^{9} \mathrm{Na}$ kraju pisma nedostaje ime. Sa strane, na levoj margini uz poslednja dva pasusa stoji rukom napisana na engleskom nova adresa prof. Petrovića.

${ }^{10}$ Pismo kucano pisaćom mašinom na engleskom. Potpisano rukom.

${ }^{11}$ Termin prenosimo u originalu smatrajući ga adekvatnijim od svakog prevoda.
} 
zato što je naglasak mnogih engleskih reči često zavisio od trenutnog ritmičkog konteksta u govoru - navedeni oblici u rečniku su jednostavno neadekvatni za mnoge reči. Evo dva kratka primera: this man is very unkínd vs. this is a very únkind man. Drugi je: that boy is red-héaded vs. did you see the réd-headed boy? ${ }^{12}$ Očigledno da pesnici osete te varijacije i iskoriste ih u svojoj poeziji. Takođe postoje engleske, američke, dijalekatske i arhaične varijacije. Takođe sam slušao neke snimke glumaca i one koje su pesnici sami snimali, ali nesistematski, i nisam ništa pročitao o tome kako stih treba recitovati. Čak i u ovom kratkom izvodu izgledalo je da se opkoračenje javlja dosta često i da ga treba uzeti u obzir zato što tada, činilo mi se, poslednji iktus retka nije jako naglašen i tretiran je kao nenaglašen u ritmičkoj analizi. Satima sam slušao snimke koje sam napravio i postepeno sam došao do sličnih zaključaka kao i ti. Jasno mi je da se tendira ka dve vrste čitalaca (među neprofesionalcima i nepesnicima) - koji poštuju pravila (koji zastaju na kraju svakog retka) i oni prirodniji (koji ne zastanu). Sve ovo je naravno samo moje nagađanje $\mathrm{i}$ ne predstavlja temeljan naučni pristup koji se postiže čitanjem priručnika o izvođenju, učenjem o glumačkom ostvarenju ili proučavanjem stiha mnogih pesnika u različitim periodima.

Možda sam spomenuo dva Jejtsova [William Butler Yeats] snimka iste pesme, jedan napravljen veoma rano kada je komentarisao da stih treba da bude različit od kolokvijalnog jezika - pročitao je u veoma povišenom, odmerenom i retoričkom načinu. Drugi snimak napravljen 1930-ih urađen je na veoma kolokvijalan način - veoma različit zvuk i ritam. Čini se da ovo potvrđuje ono o čemu si ti pisao o promeni u tradiciji negde u dvadesetom veku.

I sam sam se pitao o nečemu drugom s obzirom na dugu istoriju engleske učene poezije za razliku od relativno kratkog perioda ruske učene poezije. Takva engleska poezija postojala je mnogo pre nego što su racionalistička pravila Klasicizma postala preovlađujući način. Posebno je u elizabetanskom slobodnom stihu opkoračenje bilo uobičajeno i sa Miltonom [John Milton] je sigurno bilo prihvaćeno u narativnim pesmama. Ali to se dogodilo pre pojave klasicizma tako da je, čini mi se, već postojalo nekoliko tradicija u engleskoj poeziji. S druge strane, ruska učena poezija je stvarno postala potpuno uspostavljena tokom klasicizma kada je opkoračenje smatrano neprihvatljivim. Ako je tradicija pravljenja pauze uvek ili markiranja prekida na kraju retka tada utvrđena, da li bi imalo smisla reći da je ta tradicija možda nastavljena sve do današnjeg dana na ruskom? I dalje pitam Ruse koji dobro poznaju rusku poeziju kako oni recituju stihove sa opkoračenjem i

\footnotetext{
${ }^{12}$ Primeri su preneti u originalu kako bi se pokazalo mesto akcenta.
} 
do sada nisam pronašao nijednog koji ne uzima u obzir pauzu. U stvari, oni su čak i iznenađeni što ih to pitam.

Do svega ovoga sam došao pre nekoliko godina kada sam predao rad o Lomonosovljevoj [Михаи́л (Миха́йло) Васи́льевич Ломоно́сов] tradiciji koja još uvek utiče na rusku versifikaciju. Nameravao sam da kroz primere pokažem kako njegove osnovne pretpostavke u velikoj meri postoje do danas, mada tu i tamo poneki poeta povremeno napusti to ograničenje. Navodio sam na jednom mestu primere onoga što nazivam ,nenaglašena rima” i posebno sam citirao neke stihove Brodskog koji je, kao što znaš, dobro poznavao englesku poeziju, prevodio je i verovatno bio na neki način pod njenim uticajem. Nenaglašena rima je u engleskom prilično uobičajena i ponekad uključuje stihove u kojima je poslednja reč proklitika i stvara opkoračenje $\mathrm{u}$ narednom stihu. Takve slučajeve sam tretirao kao „proklitičke rime” i nenaglašene koji su rezultirali poslednjim nenaglašenim iktusom, što je izuzetno redak slučaj u ruskom stihu. Gasparov [Михаи́л Лео́нович Гаспа́ров] se odmah usprotivio tvrdeći da mora biti pauze tako da je rima još uvek naglašena. Istakao sam da je to stvar recitovanja a ne jezika, razlika koju su ruski metričari u velikoj meri veoma obazrivo posmatrali. Kako bi interpretirao ove stihove Brodskog?

Сплошные струпья. Высохшие и
набрякшие. Лишь слипшиеся пряди,
нетронутые струпьями, и взгляд
принадлежали школьнику, в мои
как я в его косившему тетради
уже двенадцатьлет тому назад.

(«Остановка в пустыне», с. 127)

Nenaglašena rima je fascinatna tema $u$ različitim jezicima i iako je povezana sa pitanjem o opkoračenju ne želim da pišem o tome i pismo učinim dužim nego što već jeste. Ali imam još jedno pitanje koje se tiče Lordove [Albert Bates Lord] upotrebe onoga što on naziva ,periodsko opkoračenje” (ako se dobro sećam termina). Veoma sam skeptičan po pitanju mogućnosti pravog opkoračenja $u$ pevanom narodnom stihu zato što je jezička intonacija ograničena i obično se slaže sa krajem retka i melodijom. Čini mi se da Lord pozajmljuje svoju ideju od engleskih književnih naučnika koji mešaju interpunkciju sa intonacijom i pišu nešto poput ,ako se misao prenosi u naredni red onda imamo opkoračenje”.

Kada budem završio moj trenutni projekat (prevođenje na engleski antologije ruske usmene epike), nadam se da ću se vratiti pitanju Lomonosovljevog 
kontinuiranog prisustva u ruskom stihu i napisati veliki članak. Tvoj uvid i način objašnjenja opkoračenja su mi u tom pogledu veoma korisni.

Sve najbolje u tvom poslu,

Džejms

8. мај 1997.

Dragi Džejms, ${ }^{13}$

[...]

Tvoji komentari o opkoračenju su ubedljiva demonstracija činjenice da je oblast opkoračenja velikog opsega i da implikacije njenog proučavanja mogu biti mnogo šire nego što bi poznavalac tog polja isprva pomislio. Ideja nenaglašene rime je doista provokativna; njene posledice su jasne iz tvog pisma (i mislim da je tvoje čitanje Brodskog ispravno). Dok sam proučavao opkoračenje u srpskohrvatskom nisam bio svestan važnosti onoga što ti nazivaš nenaglašena rima. Primetio sam, u nekoliko navrata, slučajeve opkoračenja koje rastavlja fonetsku reč na jedan od dva načina: proklitika / naglašena reč i naglašena reč / enklitika, i postoji studija u našoj knjizi Metrica et poetica III: Stih u pesmi, u kojoj J. Melvinger (na str. 128-132) ${ }^{14}$ sistematski razmatra te slučajeve ilustrujući ih modernom hrvatskom poezijom. Ne postoji primer za nenaglašenu rimu u njenoj studiji, ali je Nikola Šop - autor koga najčešće citira -koristi povremeno u svojoj rimovanoj poeziji; na primer, u pesmi napisanoj, mislim, tridesetih godina ovoga veka:

Isuse blagi, u doba kasnih sati,

kad još bdiju siromasi tvoji,

skromnom krojaču odvest ću te, $\underline{\text { da ti }}$

jedno obično odijelo skroji.

(,ti’ ovde nije 'you' već enklitički oblik od „tebi”, 'to you')

Ima povremenih slučajeva nenaglašene rime u savremenoj srpskoj poeziji takođe, na primer, kod izvrsnog pesnika, I. V. Lalića, koji je umro prošle godine (više njegovih pesničkih knjiga objavljeno je u engleskom prevodu u SAD-u i

\footnotetext{
${ }^{13}$ Pismo kucano pisaćom mašinom na engleskom. Nije potpisano.

${ }^{14}$ U pitanju je rad „Sintaktička, asintaktička i ostala opkoračenja u suvremenom pjesništvu”, Melvinger 1988. Na osnovu njenih istraživanja nastao je i rad o opkoračenjima u sonetima Slobodana Zubanovića. U njemu se daje primer i za nenaglašenu rimu u dve Zubanovićeve pesme (v. Paripović Krčmar 2018: 82-93).
} 
Britaniji tokom poslednjih decenija). Ipak, pojava nenaglašene rime u modernoj srpskoj i hrvatskoj poeziji - sudeći po veoma površnom uvidu koji sam bio u stanju da izvedem ovih dana - čini se veoma retkom u poređenju sa pojavom opkoračenja tipa proklitika / naglašena reč u nerimovanoj poeziji; na primer, samo na osnovu pregledanja poslednjeg, aprilskog broja beogradskog književnog časopisa $R e \check{c}$, na prvih pet strana, izbrojao sam pet takvih opkoračenja u poeziji V. Karanovića, talentovanog mladog pesnika (relativno mladog, bio je moj student, a sada je u četrdesetim). ${ }^{15}$

Čini se kao da se nešto slično - ako ne i polarizovanije podele - može opservirati u starijoj poeziji takođe. Nisam pronašao nijednu pouzdanu nenaglašenu rimu u velikom izboru od dva stara hrvatska pesnika koji su uvek rimovali i istovremeno obilno koristili opkoračenje, uključujući različite vrste jakog opkoračenja - Marko Marulić (pregledao sam njegovo glavno delo, ep Judita, 1501, oko 1800 stihova) i Ivan Mršić (ne tako značajan pesnik sa početka 17. veka; pregledao sam izbor koji sam objavio pre nekih trideset godina i nisam proverio neobjavljene rukopise); postoji nekolicina nepouzdanih slučajeva - tri kod Marulića i jedan kod Mršića - u kojima je veznik razdvojen opkoračenjem od naglašene reči, ali je nesigurno da li smo u ovakvim slučajevima u pravu ako tretiramo konjukciju kao proklitiku (upotrebljeni veznici - pak i jer -obično su u govoru nenaglašeni, a tako su i u mnogim rečnicima predstavljeni, ali su ispravno tretirani od strane mnogih lingvista kao reči koje mogu imati nezavisan akcenat). S druge strane, Lukijan Mušicki, značajan srpski pesnik s početka 19. veka, često je upotrebljavao opkoračenje tipa proklitika / naglašena reč, ali je njegova poezija nerimovana.

Naravno, moje ispitivanje dozvoljava neozbiljne zaključke o statusu nenaglašene rime u srpskohrvatskom. Moderni pesnici, naročito, izabrani su za ovaj brzi pregled potpuno nasumično i različiti izbori su lako mogli otkriti različite perspektive. Do sada je jedino jasno da se nenaglašena rima pojavljuje u srpskohrvatskom, barem u poeziji ovoga veka.

\footnotetext{
${ }^{15}$ Nakon ovog pisma u rukopisu prof. Petrovića nalazi se priložen deo časopisa Reč, br. 32, april 1997, od 5. do 32. strane, temat posvećen Vojislavu Karanoviću, ispod čijeg imena u gornjem desnom uglu stoji rukom napisana i zaokružena reč - opkoračenje. Pretpostavljamo da je primerak pripremljen za slanje ili je poslat prof. Bejliju, jer su u tekstu pesama crvenom olovkom podvučene neke reči kao primer opkoračenja tipa proklitika / naglašena reč. Isto tako, posle ovog časopisa stoji i primerak rada Jasne Melvinger „Intertekstualnost žanra i stiha u pjesmama Jovana Zivlaka i Mile Stojića”, objavljen u Rukovetima, br. 6-7, 1991, str. 450-459, gde su takođe u pojedinim pesmama podvučene reči koje se navode kao primer istog tipa opkoračenja. Moguće da je i ovaj rad poslao kolegi. U narednim pismima prof. Bejlija ne navodi se da je primio ove separate časopisa.
} 
Po pitanju Lordovog 'periodskog opkoračenja' mogu biti određeniji.

Lord koristi termin povremeno - retko (letimičnim pogledom mogu da lociram samo jedan slučaj u Pevač priča, str. 131) - kao sinonim originalnog Perijevog [Milman Parry] i lično njegovog češćeg, termina 'nužno opkoračenje'. Ovaj termin je bio u suprotnosti sa Perijevim neperiodskim opkoračenjem ['unperiodic enjambement'] ${ }^{16}$. (I sam Lord koristi ovaj oblik u svojoj glavnoj studiji o opkoračenju, „Homer and Huso III”, iz 1948, i menja ga u 'nonperiodic e'. u Pevač priča); obojica, Peri i Lord, često opisuju upotrebu neperiodskog opkoračenja kao 'stila dodavanja'.

U razumevanju terminološke distinkcije - 'nužno' ('periodsko') u odnosu na 'neperiodsko' ('stil dodavanja') - može pomoći pažljivo čitanje uvodnih strana "The Distinctive Character of Enjambement in Homeric verse" (TAPhA, v. 60, 1929), kontekst u kojem se Perijeva ideja prvobitno izrodila. Verujem da je zaista moguće rekonstruisati uz pomoć ovog ranog rada način na koji se distinkcija razvila iz Perijevog razmišljanja. ${ }^{17}$

Njegov krajnji izvor bila je razlika između 'periodskog'_i 'slobodnog stila' ${ }^{18}$, kao što je predložio Aristotel (Retorika III, 9), obrazlažući na različite načine opis stila značajnih klasičnih retora i u 19. veku veoma popularnih. U našem veku elementarni uvodi u stilistiku i značajne knjige još uvek povremeno upućuju

\footnotetext{
${ }^{16}$ Ostavljamo i originalan naziv ne bi li se uočila razlika u odnosu na pojam kojim je zamenjen (unperiodic - nonperiodic).

${ }^{17}$ U jednoj fusnoti u knjizi Pevač priča Lord potvrđuje da se drži Perijeve definicije opkoračenja i iznosi je u celosti: ,'Široko gledano, postoje tri načina na koji smisao na kraju jednog stiha može da se odnosi prema smislu na početku drugog. Prvo, kraj stiha može da se poklopi s krajem rečenice i da novim stihom počne nova rečenica. U tom slučaju nema opkoračenja. Drugo, stih može da se završi grupom reči na takav način da rečenica, na kraju stiha, već zaokružuje misao, iako se nastavlja i u sledećem stihu, nadovezujući nezavisne ideje putem novih grupa reči. Na ovaj tip opkoračenja možemo primeniti Denisov termin neperiodsko. Treće, kraj stiha može da padne na kraj grupe reči; u oba ova slučaja opkoračenje je nužno... Da bismo znali gde nema opkoračenja, moramo da procenimo rečenicu. Promenljiva interpunkcija u našim tekstovima, često vrlo zamršena, neće nam pomoći. Ja definišem rečenicu kao svaku nezavisnu rečenicu ili grupu rečenica koja počinje naporednom svezom ili asindetonom; a da bih dokazao da je ova definicija prikladna, istaći ću da su retoričari poklanjali malo pažnje rečenici onakvoj kakvu je mi shvatamo; za njih je jedinica stila bila rečenica, a jedina grupa rečenica o kojoj Aristotel govori jeste period.‘ Jakobsonova trvdnja da u srpskohrvatskoj epici nema opkoračenja, koja sledi možda poznatiju definiciju opkoračenja, tačna je, mada se mogu naći i retki izuzeci." (Lord 1990: 265-266).

${ }^{18}$ loose style
} 
na to - i opisujući strukturu rečenice mogu, bez upućivanja na Aristotela, praviti razliku između 'periodske rečenice' i 'neperiodske', ili 'slobodne', rečenice - ali se ne sećam da sam čitao iole značajnu studiju o književnom stilu napisanu tokom poslednjih decenija u kojoj je razlika upotrebljena na izrazit način. Izgleda da bi se većina pisaca koja se bavi stilom u ovom veku manje-više složila sa Dž. Sejntsberijem [George Edward Bateman Saintsbury] koji je 1900, u pola rečenice, odbacio ovu Aristotelovu ideju, kao karakteristiku „koju su moderne knjige previše eksploatisale, a koja je zaista veoma nevažan tehnički detalj“.

U zavisnosti od prevoda i različitog izbora ključnih reči koja su markirana u prvoj rečenici poglavlja III, 9, Aristotelova distinkcija je često predstavljena i drugim terminima. Umesto 'periodskog stila', ritma rečenice, itd., neki moderni prevodioci i kritičari koriste termin 'kompaktan stil' (Averincev [Сергей Сергеевич Аверинцев]: 'slog spletennyj'); 'periodski' može biti zaista zbunjujući ako se koristi izvan originalnog konteksta (gde znači govor u dobro strukturiranim periodima, ponekad podrobnije razdeljen na članove, itd.). Značajno je da Peri, u citiranoj studiji, nikad ne opisuje 'periodsko', i indirektno, (citirajući Dionisija iz Halikarnasa [Dionysius of Halicarnassus] koji govori da ,je neperiodsko, mada se izražava u klauzulama i frazama"), on takođe ukazuje na sumnju u preciznost Aristotelovog opisa prvog člana njegove distinkcije (ili, najmanje, u njegovo tradicionalno poimanje). Umesto 'slobodnog stila', nalazi stil nizanja ${ }^{19}$ (odnosi se na improvizovani stil, uporedi Averincev: 'slog nanizyvajuščj') kao alternativne nazive za drugi član Aristotelove distinkcije. Peri to priziva u toku svoje interpretacije „Denisovog termina 'neperiodsko", sa jasnom pretpostavkom da se odnosi, manje-više, na isti fenomen: ,ideje se dodaju jedna na drugu, u onom što Aristotel naziva 'running_style"” (u fusnoti: „doslovno, 'strung style' kao brojanica ili venac"). Uzgred, Perijev termin 'stil dodavanja' je direktno izveden iz ovog opisa; ideja dodavanja je glavna ideja u rečenici koju citira od Dionisija takođe. Ali Peri ne dovodi u vezu termin 'neperiodsko' sa Aristotelovim konceptom i ne znam da je iko drugi to radio u to vreme, mada je gotovo nemoguće verovati da ono što je suprotno od 'periodskog' nije privuklo takvo naziv već u 19. veku, u bilo kojem, ako ne u mnogim, od onih zbornika na koje Sejnsbori upućuje.

Otuda je u pozadini Perijeve ideje o 'nužnom' ili 'neperiodskom' opkoračenju (koje se Lord striktno pridržava čak i kad povremeno modifikuje jedan ili drugi Perijev termin, tako da je njegovo 'periodsko o'. tačan sinonim Perijevog 'nužnog o'.) teorija stila pre nego teorija stiha. Peri poseže za klasičnom retorikom

${ }^{19}$ free-running style, strung-along style 
da bi obezbedio konceptualna sredstva neophodna za opis važne odlike Homerovog stila koju je posmatrao on i mnogi drugi naučnici (u svojoj studiji citira M. Kroazea [Maurice Croiset], istoričara grčke literature sa kraja 19. veka). Ne bih želeo da tvrdim da je njegov izbor sredstava nesumnjivo najbolji (odlomci iz Aristotela i Dionisija, koje citira, sigurno nisu model nedvosmislenog teorijskog izlaganja, kao što bi se moglo razumeti na osnovu njihove sudbine u kasnijoj kritici, a postoje i alternative - na primer, 'hipotaktički' naspram 'parataktičkog stila' - koje, mislim, mogu da posluže svrsi podjednako dobro ako ne i bolje). Ipak, distinkcija koja je dobro funkcionisala unutar kostura njegove teorije o narativnom stihu usmenih pesama i u studijama koje su se ticale pitanja oralnog prema pismenom u poetskom tekstu, čini mi se deluje bolje nego one skorašnje i stvorene na istim osnovama, za koje znam (na primer, Berkli Pibodijevo [Berkley Peabody] esencijalno i neesencijalno opkoračenje, ili Kirkova ${ }^{20}$ dalja podela nužnog opkoračenja periodskog opkoračenja postaje jedno od njegovih potpodela - koja je verovatno dobro skrojena za potrebe izučavanja Homera ali izgleda da je manje potrebna ili korisna u komparativnim proučavanjima usmene tradicije).

Važno je, naravno, imati na umu da se termin 'opkoračenje' u PeriLordovoj teoriji ne koristi samo u širem smislu nego obično (postoji 'opkoračenje', u njihovoj upotrebi, kad god se kraj rečenice i kraj retka ne podudaraju), ali, ono što je važnije, je da se ono koristi u drugačijem smislu od onog koji obično implicira u književnim izučavanjima (ma koliko može biti velika raznolikost njegovih definicija i interpretacija u samim književnim proučavanjima). Zbog toga bi bilo pogrešno tretirati dve vrste opkoračenja, u Peri-Lordovom smislu, kao znak bilo dva nivoa $o$. u uobičajenom smislu, na primer: jače i slabije, ili dva stepena osetljivosti (podložnosti) na opkoračenje u običnom smislu, recimo: velika i mala verovatnoća da se javi opkoračenje. Lord je sigurno upravu kada tvrdi da je „neperiodsko o., 'stil dodavanja', karakteristika usmene pesme; dok je periodsko opkoračenje karakteristika 'književnog' stila"21: u usmenoj poeziji, delovi duge rečenice, podeljeni u dva ili više redova, mnogo su češće uzajamno udruženi na parataktičan nego na hipotaktičan način. Ali iz toga nužno ne proizilazi da treba da se očekuje izuzetna pojava pravog opkoračenja u usmenoj poeziji među relativno retkim

\footnotetext{
${ }^{20}$ Misli se na tekst G. S. Kirk ,Verse-structure and Sentence-structure in Homer”, YCS 20 (1966), 105-152.

${ }^{21}$ Ovaj citat odnosi se na Lordov članak „Homer and Huso III: Enjambement in Greek and Southslavic Heroic Song”, TAPhA, 79: 113-124 (1948). Na tu se konstataciju Lord poziva i u knjizi Pevač priča (v. 1990: 240).
} 
stihovima spojenim hipotaktički ('periodsko' ili 'nužno o.') i ne među onim povezanim parataktički ('neperiodsko o.'). Razmatrao sam vezu između Perijeve i Lordove koncepcije opkoračenja i našeg zajedničkog pojma opkoračenja u dve prilike: u mom tekstu u IJSLP 1982, na engleskom, na stranama $355-356^{22}$, sam napomenuo da nijedan od 18 primera nužnog opkoračenja_u srpskohrvatskom, koje Lord citira u njegovoj glavnoj studiji na tu temu, nisu opkoračenja u uobičajenom smislu reči; u mom tekstu, na srpskohrvatskom, u knjizi Usmeno i pisano / pismeno..., na stranama 147-150, istražujući Topićevu raspravu sa E. Stankjevičem [Edward Stankiewicz], koja se delimično bavila primenom Lordove ideje opkoračenja, napomenu sam da je jedini siguran slučaj opkoračenja u običnom smislu među primerima citiranim u toj diskusiji bio u stihovima koji bi, po PeriLordovoj terminologiji, morali biti opisani kao slučaj neperiodskog opkoračenja .

$[\ldots]$

Želim ti svu snagu koja ti je potrebna, [Sveta $^{23}$

\section{ZAKLJUČAK}

O opkoračenju kao pesničkom postupku pisao je Petrović u više navrata i različitim povodom - $\mathrm{u}$ segmentima pojedinih radova argumentuje se književnoistorijska situacija i efekti semantika stiha, dok se u dva celovita rada posvećena problematici opkoračenja ističe temeljno definisanje pojma u odnosu na postojeće definicije, razlika između uobičajenog smisla i proširenog obima pojma, kao i polemika sa dosadašnjim shvatanjima i tumačenjima što istorijskog razvoja, što pitanja prisustva ove pojave u usmenom narodnom stihu. Prepiska dvojice kolega, koja je usledila nakon ovih ispitivanja i opažanja, inicirana poklonjenim

\footnotetext{
${ }^{22}$ Misli se na Petrovićev tekst „Opkoračenje u srpskohrvatskom stihu: postojana podloga”, izvorno objavljen pod naslovom „Enjambement in Serbo-Croatian: A Stable Background”, $\mathrm{u}$ : Slavic Linguistics and Poetics. Studies for Edward Stankiewicz on his $60^{\text {th }}$ Birthday, 17 Novembar 1980 (IJSLP XXV/XXVI, 1982), 355-366. Srpskohrvatski prevod u: Godišnjak XI Odjeljenja za književnost Instituta za jezik $i$ književnost u Sarajevu, 1982, 9-20. Objavljen je i u knjizi Oblik i smisao - Spisi o stihu (2003: 231-246).

${ }^{23}$ Potpis rukom. U ovom radu izostavljamo tri naredna pisma, od 22. maja, 9. juna i 5. avgusta 1997. godine, pošto se u njima ne razmenjuju iskustva značajna za razumevanje pojma opkoračenja; pominjemo ih zbog podataka o člancima i knjigama koje kolege razmenjuju, a koji se tiču stiha, a time i uvida o ovom pesničkom postupku.
} 
separatima reanimira razmatranja pitanja opkoračenja. Ovom korespondencijom uviđa se obimnost opsega značenja ovog pesničkog postupka i otkriva posvećenost $\mathrm{i}$ veliko interesovanje prof. Petrovića prema sveobuhvatnosti pojave. Upravo takva fokusiranost na problem nadogradila je sva dosadašnja tumačenja ovog pojma, te omogućila višestruke relacije sa različitim tradicijama. Kulturološka kontekstualizacija ne samo da je indicirala raznovrsnost i definicija i realizacija pojave opkoračenja, nego je rezultirala i impliciranjem aspekta recitovanja poezije, odnosno načina čitanja stihova $\mathrm{u}$ jakom opkoračenju $\mathrm{u}$ engleskoj, ruskoj $\mathrm{i}$ srpskohrvatskoj tradiciji. Na osnovu pauze kao kriterija prof. Petrović ukazuje da u srpskohrvatskom jeziku koegzistiraju dve tradicije čitanja (ruska i engleska) u zajedničkoj evropskoj istoriji čitanja poezije, odnosno dva načina interpretacije opkoračenja u čitanju, što svedoči o postojanju dve vrste čitalaca: one koji pravi pauzu na kraju retka - više tradicionalna, staromodna i one koji ne pravi pauzu moderna, urbanija. Dakle, njegova istraživanja potvrđuju da se mesto opkoračenja u usmenoj interpretaciji na različite načine glasom markira. Rasvetljavanje pitanja opkoračenje podsticajno je i za sagledavanje pojave nenaglašene rime i njenog statusa u srpskohrvatskoj poeziji. Potom, ponovo se minucioznije razmatra veza između Perijeve i Lordove koncepcije opkoračenja i našeg zajedničkog pojma opkoračenja, čime se prethodna tumačenja u spisima o stihu preciziraju.

Sanja J. Paripović Krčmar

OBSERVATIONS ON ENJAMBMENT IN CORRESPONDENCE OF SVETOZAR PETROVIĆ

\section{Summary}

The paper presents segments of correspondence between professor Svetozar Petrović and his colleague, professor James Bailey on the complexity of enjambement. Their discussion based on the common interest has significantly contributed to this field of study, by improving all previous interpretations of the term and offering additional implications of the study. At the same time, previous observations and various points of view presented in Petrović's writings on the verse are specified. Above all, the importance of cultural contextualization of this metric phenomenon and its connection with different poetry reading traditions is emphasized.

Keywords: Svetozar Petrović, James Bailey, enjambement, end-stopped line, reading lines traditions, scansion, unstressed rhyme, necessary enjambement, nonperiodic enjambement adding style, Parry and Lord 


\section{CITIRANA LITERATURA}

Lord, A. B. (1990). Pevač priča 1(teorija), 2 (primena). Beograd: Idea.

Melvinger, J. (1988). Sintaktička, asintaktička i ostala opkoračenja u suvremenom pjesništvu. U: Petrović, S. (ured.) Stih u pesmi.Colloquia Litteraria: Metrica et poetica III. Novi Sad: VANU, 123-135.

Paripović Krčmar, S. (2018). Duh vremena u staromodnom odelu - Soneti sa sela Slobodana Zubanovića. U: Poezija Slobodana Zubanovića, zbornik radova. Novi Sad: Matica srpska, 82-93. (štampano ćirilicom)

Paripović Krčmar, S. (2018). Zapažanja o opkoračenju u spisima o stihu Svetozara Petrovića. U: Godišnjak Filozofskog fakulteta u Novom Sadu, knj. XLIII/1. Filozofski fakultet: Novi Sad, 469-483. 